\title{
The 2011 Census taking shape: the selection of topics and questions
}

Ian White and Elizabeth McLaren

Office for National Statistics

The UK Statistics Authority's proposals for the next census in England and Wales, to be taken in March 2011, were published and presented to Parliament and the National Assembly for Wales in a Government White Paper $^{1}$ on 11 December 2008. These have been published at this time some two years or more before the census itself - in order for Parliament and the public alike to be given the opportunity for informed discussion on the design of the next census, and particularly the proposed questions to be included, before the secondary legislation necessary for the census to take place is considered by Parliament towards the end of 2009/early 2010. This article - the first of two to report on the significant recent developments in the design of the census - comments on the questions that are being proposed in England and Wales and notes the degree in which these are being harmonised across the rest of the UK and how comparable they are with those asked in 2001. The main uses to which the information collected will be put are described.

A second article, scheduled for the summer issue of Population Trends, will focus on the key methodological and operational developments designed to improve coverage in the 2011 Census and the quality of the resulting statistical outputs.

\section{The decision on the 2011 Census}

The Government has decided, in agreement with the UK Statistics Authority, that the next Census of Population should be taken in England and Wales on Sunday 27 March 2011. Censuses will also be taken on the same day in Scotland and Northern Ireland subject to separate legislative procedures in the Scottish Parliament and the Northern Ireland Assembly. The 2011 Census will be the twenty-first in a series carried out every ten years in England and Wales since 1801, except in 1941.

Government, local authorities, the health service, the education and academic community, commercial business, professional organisations and the public at large all need reliable information on the number and characteristics of people and households if they are to conduct many of their activities effectively. This need is currently best met by conducting a census every ten years covering the whole of the population, and by updating the population estimates each year benchmarked on the preceding census.

Taking account of the many comments, evaluations and recommendations arising from the 2001 Census, the design of the 2011 Census is based on a number of key strategic aims:

- to give the highest priority to getting the national and local population counts right

- to maximise overall response and minimise differences in response rates in specific areas and among particular population sub-groups

- to build effective partnerships with other organisations, particularly local authorities, in planning and executing the field operation

- to provide high quality, value-for-money, fit-for-purpose statistics that meet user needs and which are as consistent, comparable and accessible across the UK as is possible, and 
- $\quad$ to protect, and be seen to protect, confidential personal census information

\section{Consultations and tests}

The topic content of the 2011 Census has been driven principally by the demands and requirements of users of census statistics, the evaluation of the 2001 Census, and the advice and guidance of organisations with experience of similar operations. These have been determined by extensive consultation, through a structure of formal advisory committees, topic-related working groups and public meetings, and via media such as ONS consultation and information papers, and the Census website.

Government departments have been consulted, both on a bilateral basis and collectively through the heads of profession of the Government Statistical Service and inter-departmental committees, to determine their needs and priorities for topics to be included. Local authorities, the health service, the academic community, the business sector and local communities were similarly consulted through long-standing census advisory groups convened by the National Statistician. Topic experts and methodologists within ONS have also been consulted.

Additional consultation with local authorities has been managed through a Local Authority Liaison Programme which is being developed through a network of census regional champions appointed from among the regional returning officers for each of the nine Government Offices for the regions of England and the Returning Officer for Wales.

In Wales, representatives of ONS and the Welsh Assembly Government attended a meeting of each of the National Assembly subject committees during the period October 2006-March 2007 to discuss plans for the census in Wales.

In addition, there have been formal public consultations supported by a number of national open meetings on particular issues.

The proposals for the census also take account of the results of a programme of research and testing aimed at better understanding of the public's comprehension and perception of census-related concepts. There have also been tests, both small- and large-scale, of census question wording, questionnaire design and delivery methods. These included a major Test carried out in May 2007 in areas in five local authorities:

$\begin{array}{ll}\text { - } & \text { Liverpool } \\ \text { - } & \text { Bamden } \\ \text { - } & \text { Stoke-on-Trent } \\ \text { - } & \text { Carmarthenshire }\end{array}$

The local authority areas were selected (as has been previously reported in Population Trends ${ }^{2}$ ) to reflect a range of field conditions and providing a varied cross-section of the population - for example containing a mix of students, the elderly, and ethnic communities - and types of housing that would be covered in a full census.

Overall response to the voluntary Test was 48 per cent and ranged from 35 per cent in Camden to 66 per cent in Carmarthenshire. The response was lower than in the equivalent 1997 Test prior to the 2001 Census, reflecting not only the trend in pre-census tests over the past 30 years for declining public participation but also that the areas chosen were biased towards those that are particularly hard to enumerate. Nevertheless, this was sufficiently high for valid statistical evaluations to be made. An evaluation of the Test is scheduled for publication in the spring of 2009 but, in the light of an early assessment of its key findings ${ }^{3}$, several of the procedures followed in the 2001 Census have been significantly revised.
Key changes included:

- delivery of the majority of census questionnaires by post

- outsourcing recruitment, training and payment of the enumeration field force, and

- reliance on a field management system to track form movement and monitor local area response rates

Additionally a rehearsal of the 2011 Census operation is being planned for October 2009 with the aim of ensuring that all the procedures for delivery and collection of the census questionnaires will be effective. The Rehearsal is currently planned to cover some 135,000 households in areas again chosen to simulate actual census-type conditions. It will encompass a cross-section of the population and types of housing, for example, areas with high levels of multi-occupancy, particular rapid growth and population movement, student accommodation, hotels and holiday accommodation, hospitals and other large communal establishments, and various ethnic minority communities. The Rehearsal areas will include 61,000 households in Lancaster (the whole local authority), 40,000 in Newham (approximately 40 per cent of the borough) and the whole of the Isle of Anglesey (Ynys Môn) covering some 34,000 households.

There will also be complementary rehearsals of the census operation in Scotland and Northern Ireland in 2009.

\section{The census questions}

The topics proposed for the census are those that have been shown to be most needed by the major users of census information and for which questions have been devised that can be expected to produce reliable and accurate data. In each case, no other comparable and accessible source of the information is available in combination with other items in the census.

Consultation on the topic content for the 2011 Census has (as ever) resulted in a much larger demand for questions than would be possible to accommodate on a census form that households could reasonably be expected to complete. Consequently a number of difficult decisions have had to be made in assessing the different requirements for information and balancing the needs for change against continuity.

In assessing which topics should be included in the census, ONS has had to consider a number of factors. The criteria for evaluating the strength of users' requirements for information were that:

- there should be a clearly demonstrated and significant need

- the information collected was of major national importance but that data was required for small population groups and/or at detailed geographical levels

- users' requirements could not adequately be met by information from other sources

- there should be a requirement for multivariate analysis (that is the ability to cross-analyse one variable against other), and

- there should be consideration of the ability for comparison with the 2001 Census wherever possible

In addition there were other factors which ONS needed to take into consideration in assessing the priorities for topics. These were:

- that the inclusion of particular questions should be shown, in tests, to have had no significant adverse effect on the census as a whole, particularly the level of public response

- that practicable questions could be devised to collect data which are of sufficient quality to meet users' requirements

- the constraints of size and design imposed by a self-completion questionnaire in respect of respondent burden and accuracy of response 
- that the census should not be used to collect data that would deliberately promote political or sectarian groups or sponsor particular causes, and

- legal constraints and/or demands imposed by domestic and European legislation

The topics that the UK Statistics Authority proposes should be included in the 2011 Census in England and Wales are listed in Box 1. The following paragraphs note some of the uses to be made of the information to be collected, highlighting those topics that are new or where revised questions are proposed.

\section{Questions to be asked at all addresses}

The first field activity of the census, to be undertaken some six to nine months before the census questionnaires are issued, will be to carry out a check of all addresses within particular designated areas in order to ensure that ONS has a comprehensive and up-to-date address list, which it can use as the basis of form delivery either by post or by enumerator. (More detail on the developments of an address register for the 2011 Census will be reported in the second article). The full postal address including postcode will then be automatically printed onto each census questionnaire making it unique to that household (or communal establishment). The householder (or manager of the establishment) will be asked to check that the address information is correct and to amend it if it is not.

As well as facilitating delivery of the census questionnaire, the address helps ensure the correct handling of the form by the field staff, and allows a check to be made on the receipt of those forms that are returned by mail. Strict confidentiality procedures will ensure that information on names and addresses will not be used to reveal to anyone outside the census organisation any information on identifiable individuals or households other than for the purposes of the census. The particular measures to be adopted to protect confidentiality will be described in the follow-up article.

The postcode of each address will enable Output Areas used for the presentation of census statistics to be defined in terms of postcodes and, in aggregated form, to be used in conjunction with other data organised on a postcode basis.

The person responsible for completing each census questionnaire will enter the name of each household resident to be included on the form. This helps to ensure that the enumeration is complete and enables any queries to be directed to the right person if it is necessary to check for any missing information.

\section{Questions to be asked of each household}

\section{Questions about housing}

The census will provide information about the accommodation occupied by each household and will, through the field operation, also identify vacant dwellings. This will demonstrate how the housing stock is being used and will provide a firm basis for assessing current and future requirements as the number and type of households change. At the local area level, in particular, the census is the only source of nationally comparable information on housing, and this is used widely in calculations of grant entitlements to local authorities. Measures of inadequate housing and overcrowding are used in deciding on levels of housing investment and in targeting programmes which address social and economic needs in urban and rural areas. The following questions will be asked.

Questions on the type of accommodation occupied by the household and whether or not that accommodation (including caravans and other

\section{Box one}

\section{Questions proposed for the 2011 Census in England and Wales}

At all properties occupied by households and for all unoccupied household accommodation:

- Address, including the postcode

For households

- Number and names of all residents whether present or temporarily absent on census night

- Tenure of accommodation

- Type of accommodation and whether or not it is self-contained

- Type of landlord (for households in rented accommodation)

- Number of rooms (and bedrooms*)

- Type of central heating*

- Number of cars and vans owned or available

For all residents in households

- Name, sex, and date of birth

- Marital status (including civil partnership status*)

- Relationship to others within the household

- Student status

- Whether or not students live at the enumerated address during termtime

- Usual address one year ago

- Country of birth

- Citizenship (passports held)*

- Month and year of entry into the UK*

- Intended length of stay in the UK*

- National identity* and ethnic group

- Religion

- Language*

- Welsh language proficiency (in Wales only)

- General health

- Long-standing illness or disability

- Provision of unpaid personal care

- Educational and vocational qualifications

- Second residences*

- Economic activity in the week before the Census

- Time since last employment

- Employment status

- Supervisor status

- Hours worked

- Job title and description of occupation

- Name of employer and nature of employer's business at place of work (industry)

- Workplace address

- Means of travel to work

For all visitors in households

- Name, sex, and date of birth

- Usual address (or country of usual residence if a non-UK resident)

For residents in communal establishments

- As for residents in household except for the relationship to others within the household

- Status of persons within the establishment

For communal establishments

- Type of establishment

Note: Topics marked* are proposed for inclusion in the census in England and Wales for the first time. 
temporary structures) is self-contained will be used to identify separate dwellings and the characteristics of the accommodation in dwellings shared by two or more households. Central government, local authorities and other users have confirmed the ongoing importance of collecting this data to facilitate analysis of changes in housing supply and demand, to understand variations in multi-occupancy and to identify deprived areas.

Questions on the tenure of accommodation and type of landlord (where the accommodation is rented) will show how much of the housing stock in each area is in owner-occupation and whether or not it is subject to purchase by mortgage, or is local authority housing, privately let, provided by housing associations, or held by other types of tenure. The information will help central and local government to assess changes in housing demand, to allocate resources and to review and develop housing plans and policies, and will be used by the housing industry in analysing the housing market and assessing possible mismatches between housing supply and demand.

A question on the number of rooms within the accommodation will help show, together with the number and characteristics of people in each household, the degree to which accommodation may be overcrowded or under-utilised. Shortage of living space (for which a count of the number of rooms provides a proxy measure) is seen as a fundamental indicator of housing deprivation and is associated with adverse personal, social and health effects and, as such, constitutes an integral part of the Indices of Deprivation. An additional question - new for the 2011 Census identifying the number of bedrooms is also proposed.

The previous long-standing census question on whether or not households have exclusive use of either a bath/shower or toilet amenities, or both, is no longer regarded as providing a sufficiently discriminative indicator in the allocation of resources for housing development and regeneration. Consequently, this question has been dropped from the 2011 Census. A question on the type of central heating will, however, continue to provide a useful indicator of basic housing standards, and the information will be used by central government, local authorities and other users to facilitate work on fuel poverty and deprivation. These long standing requirements have been reinforced by new and emerging needs for better information on renewable energy and energy efficiency.

A question, included in each census since 1971, will again ask how many cars or vans are owned or available for use by the household. The information is widely used to support work on transport policy and planning, and will, in particular, help to identify areas where private transport makes the most demand on road space, and to assess the demand for public transport and the need for new or improved roads to better manage traffic congestion.

\section{Questions to be asked of residents in households}

About a half of the questions addressed to residents in households will be asked of everyone; the questions relating to qualifications and labour force topics, however, will not apply to children aged under 16 .

\section{Basic population characteristics}

The primary purpose of the census is to give an accurate and authoritative estimate of the population in England and Wales and to show where they usually live, and so provide a new and up-to-date benchmark for annual mid-year population estimates for local areas. The classification of the population by sex, age and marital status provides a basis for actuarial tables, which allow trends in life expectancy to be monitored and which are used for a variety of purposes such as planning provisions for state pensions and life assurance. Analyses of persons in households by combinations of these characteristics and relationship within household will give information on different types of household, and will enable statistics to be produced on separate family units. Following the Civil Partnership Act 2004, the traditional question on marital status has been expanded to include response categories for civil partnership status.

\section{Migration}

A question, included in each census since 1961, will ask the usual address of each person one year before the census. Where this is different from the current usual address, statistics will be compiled to give the numbers and characteristics of people and households who have moved from one area to another. The figures will show arrivals from outside the UK in the year before the census but not (of course) those leaving. Additional questions new to the census in 2011 will ask month and year of entry to the UK and intended length of stay in the UK (the latter is subject to further testing and development) for all those persons born outside UK, as a means of better establishing residency status.

This information is particularly important since migration accounts for much of the growth or decline of the population of areas between censuses. The information collected in the census will allow inferences to be made about the level and pattern of migration in other years. It is most important for this purpose that there is a complete count and a better understanding of the number of people and households moving in the year prior to the census, particularly short-term migrants - the estimation of which was a focus of particular concern to the Treasury Committee in its recent report on Counting the population ${ }^{4}$. The census is the only current source of reliable migration data for small areas, and analysis of migrants by their demographic characteristics and type of move provides more information on this important group of people for planning purposes than is available from any other source.

Information from the traditional question on country of birth will provide information on people resident in the UK born in England, Wales, Scotland or Northern Ireland or elsewhere. Together with a new question to identify citizenship, the information will provide estimates of the numbers and circumstances of (sometimes small) immigrant communities from various countries, who may have particular needs.

\section{Second residence}

One of a number of key components that ONS is developing to improve coverage in the census and to better understand the reasons for undercoverage is to build more ways of assessing residency into the content of the census by introducing further questions on residence arrangements, particularly multiple residence. To that end, new questions asking about second residence and the reasons for staying at such an address are being proposed for the first time, so that population estimates can be better based on where people are usually resident.

\section{Cultural characteristics}

A question on ethnic group was first included in a census in England and Wales in 1991. The information has enabled national and local government and health authorities to allocate resources and plan programmes taking account of the special needs of ethnic minority groups. In particular, response to the question has provided baseline figures against which the Government can monitor possible racial disadvantage within minority groups. The question worked well then and also in 2001 when it was revised both to meet users' requirements for additional information about people of mixed origin and sub-groups within the 'White' population (particularly the 'Irish') and to be as acceptable as possible to respondents. The classification of ethnic groups used in the census is now widely regarded as a standard for inter-censal surveys and ethnic monitoring purposes.

It is proposed to include a question again in the 2011 Census to meet a wide range of uses of ethnicity data, particularly: 
- to enable organisations to meet their statutory obligations under race relation and equal opportunities legislation (where other sources of data do not adequately provide accurate data for small, geographically dispersed ethnic minority populations)

- in the formulae for grant allocation by central and local government

- to inform policy development and monitoring, and

- to provide public bodies with a better understanding of the communities they serve and hence inform service provision

The response categories (see Figure 1) have been developed from the frame of the 2001 Census question to meet changing user requirements and include 'Gypsy and Irish Traveller' and 'Arab', but the question continues to adopt that mix of geographic origin and colour

\section{Figure 1}

The proposed 2011 Census questions on ethnicity and national identity

(a) Ethnicity question in England

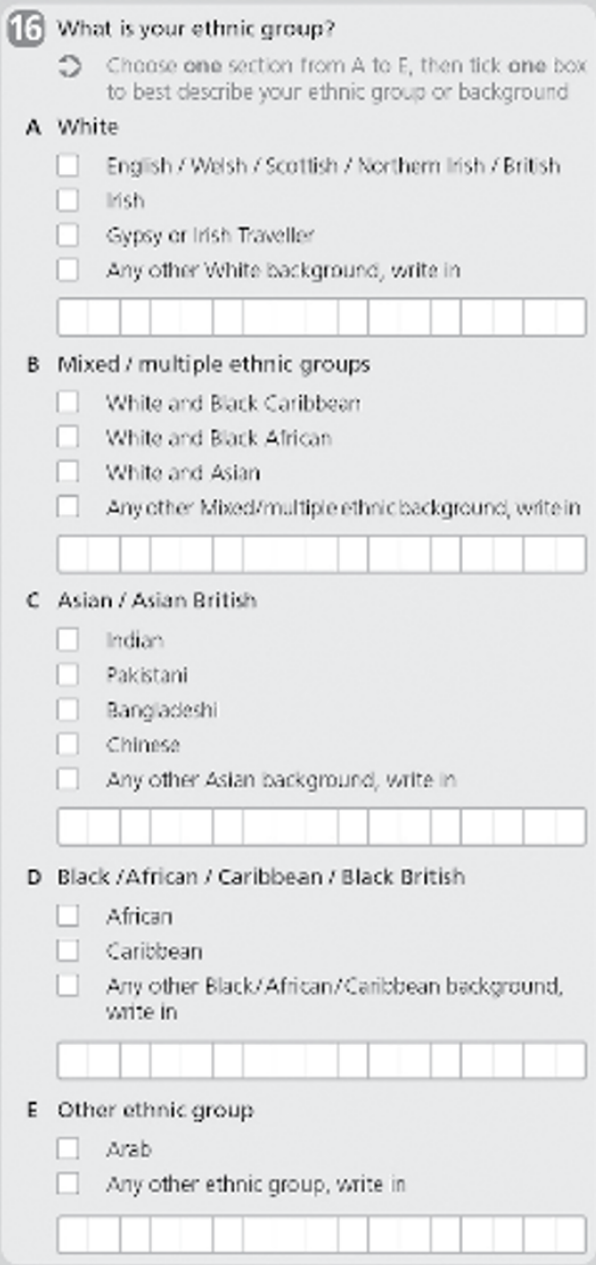

(b) National identity question in England

15 How would you descrile your natianal identity? 2 Tick al tiat apaly

ringlish

wels-

Scotish

Nothern Irish

Bitsh

other, vrite in characteristics that testing in the 1980s and 1990s had shown to be publicly most acceptable and from which the most useable statistics could be obtained.

Whilst ethnicity is clearly a dynamic characteristic when considered nationally - and the census must seek to reflect this - an equally important criterion is the ability to compare the results from one census to another - and to that end the question must retain a degree of stability over time. However, in order to make provision for people, regardless of their broad ethnic group, to indicate their identity as being British, English or Welsh (or Scottish or Northern Irish, etc), a new additional and separate component to the question will ask about national identity (for the questions in Wales the categories/tick boxes for 'English' and 'Welsh' will be transposed).

A voluntary question on religion was included in the census in England and Wales for the first time in 2001 and responses helped provide information that supplemented the output from the ethnicity question by identifying ethnic minority sub-groups, particularly those originating from the Indian subcontinent, who prefer to identify themselves in terms of their religion. Information is used to improve understanding of local populations and markets for service planning and to promote legal obligations under equality legislation and to prevent discrimination.

Religion (see Figure 2) will be one of a suite of questions that will allow individual respondents to indicate their identity in the way they consider most appropriate. No change is proposed other than re-naming the 2001 'None' box to read 'No religion'.

For each of the ethnicity, national identity and religion questions, the formats being proposed in Scotland and Northern Ireland are different - reflecting local requirements and populations - but are sufficiently comparable for the purposes of providing broad UK statistics.

A question on Welsh language will be asked in Wales - as has been done in one form or other since the 1891 Census. Responses will be used to measure the change in Welsh language proficiency to inform policy development and monitoring. The information is also used to inform local resource allocation. Similar questions with respect to the use of Gaelic will be asked in Scotland, and of Irish and Ulster Scots in Northern Ireland.

Additionally, new questions in the 2011 Census on language will, throughout England and Wales, enquire into the main language used and (for those whose main language is not English) ability in speaking English. The question on main language will enable respondents to record their main language (including sign languages) if this is not English (or English or Welsh in Wales) (see Figure 3). Responses will provide an indication of areas and communities where foreign language service provision is necessary, and to better understand the diversity of the population and, in particular, the impact of English (or Welsh) language ability on employment and other social inclusion indicators.

\section{Health}

A question, a form of which was included for the first time in the 1991 Census and repeated in 2001, will ask whether or not a person has any long-standing health problem or disability that causes difficulties in doing day-to-day activities. The information will be used as a measure of the need for health and personal social services at national and health/ local authority level, and around particular local facilities, either existing or planned. In line with the requirements arising from the Disability Discrimination Act 1995, the 2011 question will encompass both disability and illness.

The question will enable the census to provide information on the circumstances in which the long-term sick and disabled live - for 
(a) England

20

\begin{tabular}{l} 
What is your religion? \\
$\square \quad$ This question is voluntary \\
$\square \quad$ No religion \\
$\square \quad$ Christian (including Church of England, Catholic, \\
Protestant and all other Christian denominations) \\
$\square \quad$ Buddhist \\
$\square \quad$ Hindu \\
$\square \quad$ Jewish \\
$\square \quad$ Muslim \\
$\square \quad$ Sikh \\
$\square \quad$ Any other religion, write in \\
\hline
\end{tabular}

(b) Wales

20 What is your religion?

$\Rightarrow$ This question is voluntary

$\square$ No religion

] Christian (all denominations)

$\square$ Buddhist

Hindu

Jewish

\section{Muslim}

Sikh

Any other religion, write in

\section{Figure 3}

The proposed 2011 Census questions on language

\section{(a) England}

\section{8}

\section{What is your main language?}

English $\Rightarrow$ Go to 20

Other, write in (including sign languages)

\begin{tabular}{|l|l|l|l|l|l|l|l|l|l|l|l|l|l|l|}
\hline & & & & & & & & & & & & & & \\
\hline
\end{tabular}

(19)

How well can you speak English?

verywell Well Notwell

Not at all (b) Wales

18 What is your main language?

$$
\begin{aligned}
& \square \quad \text { English or Welsh } \Rightarrow \text { Go to } 20 \\
& \square \quad \text { Other, write in (including sign languages) }
\end{aligned}
$$

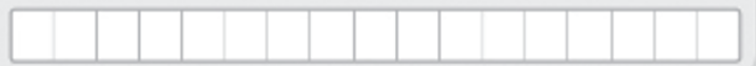

19 How well can you speak English?

verywell Well Notwell Not at all

example, whether they live alone or in unsuitable accommodation. It will also provide analysis by age, which will be important as the number of elderly people increases. The information will be of value both to the public and private sectors in providing services to sick and disabled people.

In addition, a general health question will ask the respondents to assess their own health over the preceding 12 months on a five-point scale ranging from 'Very good' to 'Very bad'; this expands the three-response categories from the 2001 Census question. This information has been demonstrated in surveys to have a good predictive power for health policy and provision of services, particularly for the elderly, and its inclusion in the census in 2001 for the first time enabled such information to be applied at the local area level.

The 2001 Census information on carers has helped to identify key policy issues affecting carers and resulted in the development of policy initiatives in relation to better support for carers from health professionals, delivery of health care, assessment of progress towards better population health, and reduction of health inequalities. The data is also used to develop and monitor policies to promote equality of opportunity, to analyse the possible burden that could be placed on social care services if unpaid carers were not available, and to identify the number of people with caring responsibilities who are not in contact with a carers support network. Its inclusion again in 2011 will help to improve the understanding of variations in the need for care and the pressure on social services in an attempt to target resources more effectively. The question will record whether or not the person provides unpaid personal help for a friend or relative with a long-term health problem or disability, and the time spent each week providing such care.

\section{Qualifications}

The information from a question on educational and vocational qualifications will be used to assess educational achievement and labour market participation across the population, looking at demographic groups at a local and regional level and the particular barriers faced. This will help users to understand and respond to equality and diversity issues, in order to widen participation and fair access. Information on those people with no or low levels of qualification are used, for example, in deriving indices of deprivation which are used across central government and by public and voluntary sector organisations as the primary basis for identifying deprived areas for funding allocations and applications. The separate 2001 question on whether people have professional qualifications such as teaching, medical, nursing and/or dental qualifications, is not being retained, although there will be a category for 'professional qualifications' to be recorded. 


\section{Employment and the labour force}

The census is a primary source of information about the socio-economic characteristics of the population and is the most comprehensive source of labour market data both at the local level and for sub-groups of the population, for which sample sizes in the Labour Force Survey are too small to provide reliable estimates. It provides statistics about the ages and occupations of workers in different industries. These statistics can be presented both by place of residence and, for those in employment, by place of work.

The census further provides statistics on the pool of labour and the potential reserves of labour in all areas. Particular applications include projections of the future labour force, use by local authorities in drawing up their structure plans, and use by private sector employers wishing to locate operations in areas where there is suitable labour.

A number of questions will be asked in order to determine the economic activity in the week before the census identifying those who are:

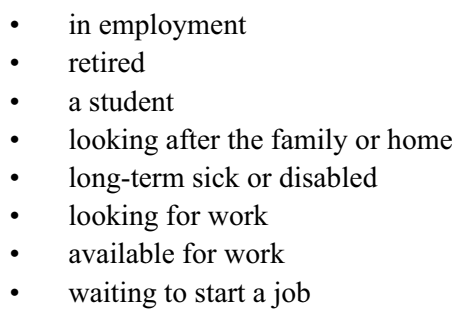

The question, new to the census in 2001 asking, for those persons who stated that they were not working in the week before the census, the year in which they last worked, will be included again. This will help determine local differences in the periods of unemployment experienced and the extent of long-term unemployment. Use of the information includes assessing and monitoring disadvantage and exclusion, planning education and training, resource allocation, labour market analysis, and in studies of mortality and morbidity.

Asking people about their full job title and the main things done in their job, will provide detailed and important information about the very wide range of work both nationally and locally. The statistics will be used in analyses of the labour forces of various industries and occupations, and in studies of occupational mortality, and will provide the basis for the classification of people and households according to the National Statistics Socio-economic Classification (NS-SEC).

Two further separate questions on employment status and supervisor status will enhance the information collected on main occupation, and responses will help in assigning the person more accurately to the NS-SEC.

Industry of occupation will again primarily be determined by asking people the nature of the business of the organisation that employs them, but some additional information may be obtained from the name and address of their employer. The information will be used, for example, in labour market analyses and in the production of regional accounts and economic indicators.

A question on the number of hours usually worked in the person's main job will distinguish those in full- and part-time work. The information will help to provide a better understanding of changes in working patterns, and how these apply to particular occupations and industries. At the local government level, information on people working long hours is an indicator of deprivation and can inform neighbourhood renewal strategies. Use of the information will also be made in labour market studies, in rural policy and regeneration, and in the derivation of area and socio-economic classifications.

Responses to a question on address of place of work will show the destination of individual journeys to work in relation to the usual address (which will normally be the origin of the journey) and will provide information on the numbers travelling to work from particular origins to particular destinations. Together with information from the question on means of transport to work, the data will help to identify commuter routes that are subject to higher loads of public and private transport.

\section{Questions to be asked of visitors}

Whereas the 2001 Census did not seek to collect information on persons who were present on census night at an address where they were not usually resident, the 2011 Census will include such 'visitors' on the household questionnaire. However, only limited information on name, sex, date of birth and usual address (or country of residence for non-UK residents) will be collected since those visitors who are resident elsewhere in the UK will also be required to supply full information on the census questionnaire at their usual address.

\section{Arrangements for communal establishments}

The Census will enumerate all people resident on census night in communal establishments such as hospitals, nursing and residential homes, educational establishments and hotels, etc. (residency in such establishments will be determined on the basis of a length of stay of six months or more). Full particulars will be collected for residents in such establishments, and statistics on these residents will be prepared for each type of establishment, separately identifying resident staff. Communal accommodation is becoming increasingly widely dispersed in small units, which are difficult to cover in sample surveys. The census provides a comprehensive and authoritative count of the population living in these establishments that is not available from other sources.

Information will not be collected relating to the person's relationship to any other person within the establishment nor their accommodation (although data about the type of communal establishment will be collected separately from the manager or other person in charge of the establishment).

\section{Topics considered but not included in the proposals for the 2011 Census}

In addition to the questions set out above, the UK Statistics Authority considered many other topics that had been suggested for inclusion in the 2011 Census, but did not include them because:

(a) the case for them was not considered strong enough to displace one or more or the proposed topics, or

(b) tests had showed that the quality of the information obtained from a census question would not be fit for purpose, or

(c) the questions would place too great a burden on the public, or

(d) a combination of these reasons.

The topics that were considered but are not included in the proposals are listed in Box 2. ONS carefully evaluated all the suggestions submitted. Some topics were rejected at an early stage in planning but many were subjected to both small- and large-scale testing. Foremost among these were questions on income and sexual identity.

\section{Income}

As was the case prior to the 2001 Census, consultations with users indicated a widespread requirement to have information on level of 
individual gross income available from the 2011 Census. Income is widely seen as a more discriminating variable than occupation or housing condition for the purposes of identifying areas of affluence or deprivation and in economic and social research. All main user communities made a strong case for a question on income in their business cases for census topics. In particular, central and local government users expressed a requirement for the information to be used to support a range of activities including resource allocation, policy development and review, the derivation of deprivation indicators, and in the assessment of inequalities and social exclusion.

Aware of the concerns that arose in attempting to include the topic in the 2001 Census, an income question was included in the 2007 Census Test with the aim of assessing whether or not there was significant evidence of continued public disquiet about the inclusion of such a question in the Census which would be likely to affect response rates.

As reported earlier ${ }^{2}$ the design of the Test allowed for the effect that the inclusion of a question on income would have on the response rates to be assessed. Half of the 100,000 households covered in the Test received a census questionnaire which included an income question, and a form without the income was sent to the other half. The difference in response rates was 2.7 percentage points ( 50.6 per cent for forms with the question compared with 53.3 per cent for those without). This difference was similar to that experienced in the pre-2001 Census tests and was statistically significant, particularly so when account is taken of the fact that the Test was voluntary and that responses were thus from households likely to be more compliant. Moreover, an analysis of the returned completed income questionnaires ${ }^{5}$ indicated that a further 9 per cent of responders elected not to answer the income question.

In balancing the user demand for information on income against this evidence of the public's reluctance to answer the question together with the evaluation of a number of other criteria aimed at assessing the public's understanding of the question and the potential availability of information from alternative sources, the UK Statistics Authority concluded that the case for including the question in the 2011 Census is insufficient to outweigh the risk of reduced response.

Public concern in Scotland about the inclusion of an income question was not so evident in the Scottish 2006 Census Test, and plans to include a question on household income in the rehearsal in Scotland have been announced $^{6}$. However, The Registrar General for Scotland will use the opportunity of the rehearsal to further assess public attitudes, and will omit the question from the census in Scotland if evidence suggests that it is likely to harm response rates there also.

\section{Sexual identity}

Consultation with users, particularly during the 2005 programme, indicated a strong requirement for the census to seek to collect information on sexual identity in order to provide a benchmark against which equality monitoring policies could be better assessed. While the UK Statistics Authority has recognised the potential value of such information, it must also take account of particular concerns about individual privacy and confidentiality within the household environment in the context of a compulsory census, the quality of the resulting data, and the effect that such a question could have on the overall response to the census.

In a small-scale postal survey carried out by the General Register Office (GROS) in Scotland in 2006, which included a question on sexual orientation, of the 31 per cent of households that responded one in seven did not provide useful data on sexual orientation - either because they elected to tick the 'prefer not to answer' box or declined to complete the question at all ${ }^{7}$. This far outweighed the percentage of respondents who

\section{Box two}

\section{Topics considered but not included in the proposals for the 2011 Census}

- access to a garden or yard

- access to bank account

- access to bath/shower

- accommodation on more than one floor level

- address five years before the Census

- age of dwelling

- asylum or immigration status

- commuting address

- Cornish language and identity

- country of previous usual residence

- duration of residence at current address

- duration of residence in UK

- educational attainment

- email address

- fertility

- frequency of use of Welsh language in Wales

- furnished accommodation

- income

- Internet access

- lifestyle

- means of travel to, and location of, place of education

- National Insurance number

- nature of long-term illness or disability

- number of current jobs

- number of miles travelled per year

- occupation group and industry using a closed (tick box) question approach

- parents' country of birth

- pet ownership

- place of birth

- presence of smoke alarms

- proficiency in foreign languages

- qualification or training required for occupation

- receipt of unpaid personal care

- sexual identity

- Sikh and Kashmiri ethnicity

- size of workplace

- taught languages

- term-time address of former students one year before Census

- type of disability

- type of tenancy agreement

- use of childcare facilities

- use of renewable energy resources

- use of wheelchair

- value of the home

- voluntary work

- state of repair of accommodation

declared a non-heterosexual orientation, and GROS concluded from this that the results would call into question the accuracy of any data gathered by such a question in the census and hence the utility of the data collected in this way. Furthermore, the terminology and concepts used to attempt to distinguish different sexual behaviour tend to confuse many respondents leading to additional inaccuracies in the responses.

In the light of this, and of other international research into the viability of including such a question in a population census ${ }^{8,9}$, the UK Statistics Authority took the view that that a compulsory census is not a suitable 
means to collect sexual identity information for the first time and that a question on sexual identity should not be included in the 2011 Census.

However, in recognition of the particular importance of collecting information on this topic for equality monitoring purposes, ONS initiated a project in 2007 to develop a question on sexual identity which will be both acceptable and ensure that high quality data is collected, and which can be used in national surveys. The main advantage of collecting this data in a household survey is the superior quality of the estimates produced. In a survey environment, information will be supplied by the person to whom it pertains and will not be shared by other householders. Privacy and confidentiality were the key concerns expressed in the focus groups by both the lesbian, gay and bisexual (LGB) and heterosexual groups.

In a press release in December 2008, ONS announced that following the recommendation of its review of equality data ${ }^{10}$, it will collect data on sexual identity in its major continuous surveys from January 2009. In this way, estimates should be available about three years earlier than any 2011 Census counts. Survey estimates can be updated annually, enabling regular monitoring of the size, distribution and changing socialdemographic profile of the LGB population.

\section{Comparability with the 2001 Census}

The main differences between the set of household and individual questions proposed for the 2011 Census in England and Wales and those asked in 2001 are set out in Box 3. However, there are, additionally, two definitional changes that may affect, to varying degrees, statistical comparisons between the two censuses.

\section{Population base}

Traditionally each decennial census covers all the people in England and Wales, and this is again proposed for the 2011 Census. Prior to the 2001 Census the enumeration base was those persons who were present at an address on census night, and counts of residents were estimated by transferring visitors back to the area of their usual residence. But in consultation on the 2001 Census, users had expressed a strong preference for the census to count persons at their place of residence whether or not they were actually present there on census night and this change was thus made. A decision was also made at that time not to count visitors in order to reduce the burden on the public.

There was some evidence, however, that this failure to attempt to capture visitors and the resulting lack of clarity as to where visitors should be recorded were two factors that contributed to undercoverage in the 2001 Census. Consequently, although ONS proposes again to enumerate persons where they are usually resident, information on visitors present in households on census night - including overseas visitors - will also be collected (see above) and separate counts produced.

Thus for 2011, all UK residents will be enumerated at the address where they are usually resident at the time of the census; the return for a household will also include anyone normally resident there who happens to be away on census night, whether elsewhere in the UK or abroad. Visitors will be allocated to their place of usual residence. The resulting counts of the number of people usually resident in an area will form the basis of the population figures used in calculating central government revenue support allocations to local government and health authorities. Because of the importance of making these figures as accurate as possible, people in households where no one was present on census night will be required to complete a census questionnaire on their return to their usual residence, if this is within six months of census night. Absent households that do not complete a census return within this period are likely to be imputed as part of the coverage assessment process $^{11}$.

\section{Household definition}

For the 2011 Census, ONS is adopting a revised definition of what constitutes a household, with the aim of improving response rates, particularly at addresses with multi-occupancy.

In the 2001 Census (and the previous census), enumerators were instructed to deliver a census form to each individual household being defined as: either 'one person living alone' or 'a group of people (not necessarily related) living at the same address with common housekeeping'. For this purpose 'common housekeeping' was defined as: 'sharing at least one meal a day or sharing a living room or sitting room'. However, difficulties were encountered by householders in interpreting the definition of a 'household'. This, together with the proposed move to a predominantly post-out methodology with its concomitant loss of doorstep contact, meant that, for the 2011 Census, a more intuitive definition of household was required. In particular, it was felt that the term 'common housekeeping' was becoming increasingly outmoded and misunderstood. Further consultation with users, and a research and testing programme with the public, was undertaken in order to devise a more readily understood concept that both reflected social change and modern living conditions, particularly within the circumstances of multi-occupied dwellings, and yet was consistent with the harmonised definition that was recommended for use in government surveys. As a consequence the following definition is being adopted in the 2011 Census Test:

A household is: one person living alone; or a group of people (not necessarily related) living at the same address and sharing cooking facilities and who also share a living room or sitting room or dining area.

\section{UK harmonisation}

As noted above, censuses are also being carried out in Scotland and Northern Ireland on the same day in 2011. While the requirements of users in each country have also to be taken into account, officials in the three census offices in ONS, GROS and NISRA have been working closely together to ensure as much comparability of topics and questions. The aim is to maximise the harmonisation of statistical outputs across the UK, to fulfil not only the commitment of the National Statistician and the Registrars General to meet domestic users' need for UK outputs ${ }^{12}$, but also the UK's obligation to provide consistent statistics to Eurostat and the United Nations.

Box 4 summarises the degree of harmonisation across the UK for those topics and questions that are currently being planned for the 2009 Rehearsal. The questions for the 2011 Census itself will not be finalised until Parliament and the devolved administrations approve these in secondary legislation, towards the end of 2009/early 2010. 


\section{Box three}

\section{Comparisons between the 2001 and proposed 2011 Census household and individual questions in England and Wales}

\begin{tabular}{l|l|l|l|l|}
\hline Topic/question & \multicolumn{2}{|c|}{ Included in 2011 Census } & \multirow{2}{*}{$\begin{array}{l}\text { Included } \\
\text { in } 200\end{array}$} \\
\cline { 2 - 3 } & \multicolumn{2}{|c|}{$\begin{array}{c}\text { Comparability with 2001* } \\
\text { in } 201\end{array}$} \\
\cline { 2 - 3 } & Full & Partial & New & in \\
\hline
\end{tabular}

Demographic topics

Sex

Date of birth

Marital status

Civil partnership status

Relationship within household

Student status

Term-time address for students

\section{Migration topics}

Country of birth

Month/year of entry to UK

Intention to stay

Address 1 year before census

Citizenship

Second residence

\section{Cultural topics}

National identity

Ethnicity

Religion

Welsh language (Wales only)

Language

Health-related topics

General health status

Long-term illness/disability

Provision of care

\section{Education topics}

Qualifications

Professional qualifications

\section{Labour market topics}

Economic activity status

Time since last employment

Employment status

Supervisor status

Hours worked

\section{Occupation}

Industry

Workplace address

Number of employees at workplace

Means of travel to work

Household accommodation and amenities

Tenure of accommodation

Type of accommodation

Type of landlord

Number of rooms

Number of bedrooms

Lowest floor level of accommodation

Type of central heating

Number of cars/vans

Amenities (bath/shower/WC)

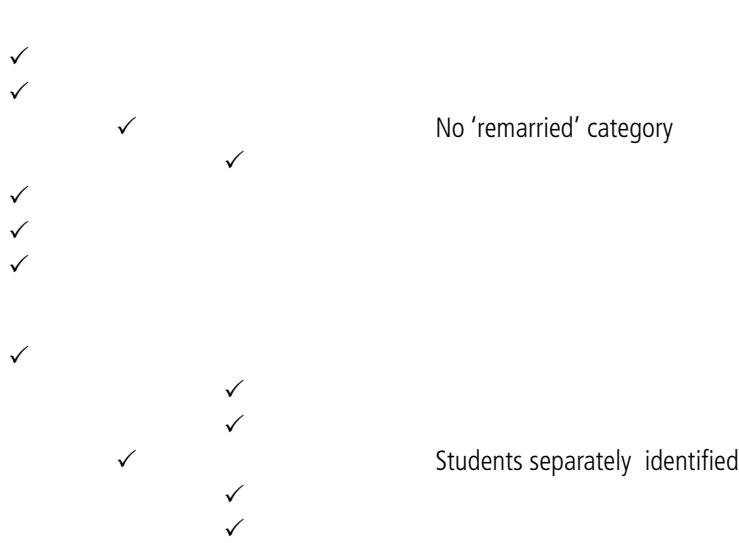

Additional 'White' category for 'Gypsy or Irish Traveller'; 'Chinese moved to 'Asian' group; category of 'Arab' added to the 'Other' group

Five-point scale response

'Yes' response, further sub-divided

New response categories added including 'foreign qualifications' Now included in main qualifications question

Four tick-box response categories would not fully correspond to 2001 outputs

* Full comparability across the UK = more or less the same question in both censuses

Partial comparability across the UK = same topic but different question wording or responses categories, which would cause some loss of statistical comparability 


\section{Box four}

\section{Harmonisation of the proposed 2011 Census questions across the UK}

\begin{tabular}{|l|l|l|l|l|l|}
\hline Topic/question & \multicolumn{3}{|c|}{ Comparability across the UK* } & \multirow{2}{*}{ Major differences } \\
\cline { 2 - 4 } & Full & Partial & Incomplete & None &
\end{tabular}

\section{Demographic topics}

Sex

Date of birth

Marital/civil partnership status

Relationship within household

Student status

Schoolchild and full-time students separately identified in Scottish

Term-time address for students rehearsal, but may be harmonised in 2011

\section{Migration topics}

Country of birth

Month/year of entry to UK

Intention to stay

Address 1 year before census

Citizenship

Second residence

\section{$\checkmark$ \\ $\checkmark$
$\checkmark$
$\checkmark$}

Question in Northern Ireland limited to entry to Northern Ireland

$\checkmark \quad$ Not included in Scotland

$\checkmark \quad$ Not included in Scotland

$\checkmark \quad$ England and Wales only

\section{Cultural topics}

National identity

Ethnicity

Religion

Welsh language

Main language

Proficiency in English

Health-related topics

General health status

Long-term illness/disability

Nature of long-term illness/disability

Provision of care

\section{Education topics}

Qualifications

\section{Labour market topics}

Economic activity status

Time since last employment

Employment status

Supervisor status

Hours worked

Occupation

Industry

Workplace address

Means of travel to work

Household accommodation and amenities

Tenure of accommodation

Type of accommodation

Type of landlord

Number of rooms

Number of bedrooms

Type of central heating

Number of cars/vans

Accessibility for disabled

Household income
Different question designs in Scotland and Northern Ireland Different response tick boxes in Scotland and Northern Ireland Some different response tick boxes in Scotland and different question design in Northern Ireland

$\checkmark \quad$ Wales only. Questions to be included on Gaelic in Scotland and on Irish and Ulster Scots in Northern Ireland

Question on 'language other than English used in the home' to be asked in Scotland

Question in England, Wales and Northern Ireland to be asked only of those

$\checkmark \quad$ Not in England and Wales

$\checkmark \quad \begin{aligned} & \text { Different response categories in Scotland and Northern Ireland to reflect } \\ & \text { different educational Systems and treatment of foreign qualifications }\end{aligned}$
different educational Systems and treatment of foreign qualifications

Open (write-in) question to be included in Scotland

Scotland and Northern Ireland to include address of place of study Some different response tick boxes in Scotland and Northern Ireland, where question also includes travel to place of study whose main language is not English

* Full comparability across the UK = more or less the same question for all countries

Partial comparability across the UK = same topic but different question wording, which would cause only minor loss of statistical comparability Incomplete comparability = topic where questions would be significantly different and would enable only a broad level of statistical comparability No comparability = question would not included in one or more countries 


\section{References}

1 Cabinet Office (2008). Helping to shape tomorrow. Cm 7513. The Stationary Office. ISBN 978-0-10-175132-2.

2 Benton, $\mathrm{P}$ et al (2006). 'The 2007 Census Test: a major step forward towards the 2011 Census'. Population Trends 126, pp 16-28. Palgrave Macmillan. ISBN 978-0-230-00321-4.

3 Office for National Statistics (2008). 2007 Census Test Evaluation: key lessons learned. www.ons.gov.uk/census/2011-census/2011-censusproject/2007-test/index.html

4 Treasury Select Committee report on Counting the population (2008). Available at: www.publications.parliament.uk/pa/cm200708/ cmselect/cmtreasy/1032/103202.htm

5 Office for National Statistics (2008). 2007 Census Test income question evaluation report. www.ons.gov.uk/census/2011-census/2011-censusproject/2007-test/income-evaluation/index.html

6 Scottish Government Statement (2008). Scotland's Census 2011. SG/2008/214. ISBN 978-1-874451-78-8.

7 General Register Office for Scotland (2006). Sexual orientation in the Census. www.gro-scotland.gov.uk/files/sexual-orientation-in-thecensus.pdf
8 Statistics New Zealand (2003). Sexual orientation Focus Group Research: a qualitative study. www.stats.govt.nz/developments/sexual-orientationresearch.htm

9 Statistics Canada (2004). 2006 Census Content Consultation Report www.statcan.ca/bsolc/english/bsolc?catno $=92-130-X$

10 Office for National Statistics (2008). Review of Equality Data Report. www.ons.gov.uk/about-statistics/measuring-equality/equality-datareview/index.html

11 Abbott, O (2007). '2001 Census coverage assessment and adjustment strategy'. Population Trends 127, pp 7-14. Palgrave Macmillan. ISBN 978-0-230-52612-9.

12 Office for National Statistics, General Register Office for Scotland, Northern Ireland Statistics and Research Agency (2006). The conduct of the 2011 Censuses in the United Kingdom: statement of agreement of the National Statistician and the Registrars General for Scotland and Northern Ireland. Available at: www.statistics.gov.uk/census/2011Census/2011project/ default. asp 